\title{
Labour and Multi-factor Productivity Analysis and Their Impact on Operations: A Case Study of a Large Poultry Farm*
}

\author{
Ram Roy \\ Eastern Institute of Technology, Hawkes Bay, New Zealand
}

\begin{abstract}
This paper investigates a large integrated poultry farm in terms of its operations, its labour, and multi-factor productivity based on the operations data received from two processing plants over a period of 15 months. The purpose of this paper is to: (a) identify and classify various types of costs that impact the operational success of the farm; (b) collect data, compute labour productivity, multi-factor productivity, rejects, and losses for the two plants; (c) compare the two processing plants of the company from various perspectives, such as rejection in products, process losses, and different types of costs; and (d) recommend ways to improve the productivity and operations of the processing plants to produce good quality products and reduce wastes during the production.
\end{abstract}

Keywords: labour and multi-factor productivity, poultry farm, waste minimization

\section{Introduction}

The creation of goods and services requires changing the raw materials and resources into goods and services through a series of processes or departments as shown in Figure 1 which is a general representation of any manufacturing plant. The more efficiently the plant makes these changes, the more productive the plant is, and the more value it adds to the goods or services provided to the customers. Improving productivity means improving efficiency of production (Heizer \& Render, 2008).

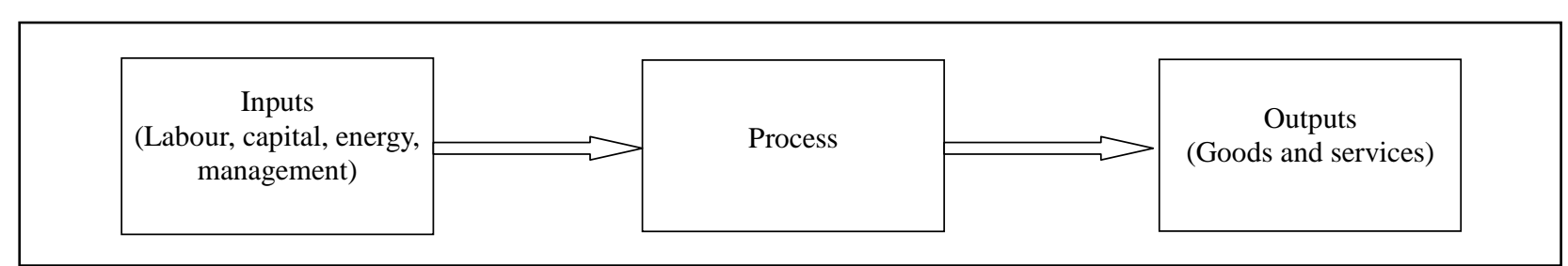

Figure 1. Input-output model of productivity. Source: Heizer and Render (2008).

Productivity analysis has been carried out by many companies in their own specific contexts and has become the most important, due to the hypercompetitive business environment. Every organization identifies

\footnotetext{
* Acknowledgement: The author acknowledges the support of SFCL for making their operational data available for productivity analysis and this paper. The author also expresses sincere thanks to Eastern Institute of Technology, Hawkes Bay, New Zealand for encouraging research activities with all the support. Local firms from Hawke's Bay can get a good perspective from this overseas operations based analysis and should feel encouraged to get such analysis done for the optimal use of their resources, too.

Ram Roy, Ph.D., senior lecturer in management, Eastern Institute of Technology, 501 Gloucester Street, Napier, 4112, New Zealand.

Correspondence concerning this article should be addressed to Ram Roy, Eastern Institute of Technology, 501 Gloucester Street, Napier, 4112, New Zealand. E-mail: rroy@eit.ac.nz.
} 
some key elements of productivity analysis depending on its operational variables; however, the two important efficiency measurements have generally been the labour and multi-factor productivity as discussed in the literature review.

\section{Literature Review}

Productivity is generally defined as the ratio of outputs to inputs, but there are different interpretations of productivity in different contexts. According to Sigala (as cited in Jones and Siag, 2009), productivity is an umbrella concept including efficiency, effectiveness, quality, predictability, and other performance dimensions, and also as a concept reflecting only production efficiency. Measuring productivity has its own challenges, for example, Anderson (as cited in Jones and Siag, 2009) identified three key difficulties in productivity measurement, viz. identification of appropriate inputs and outputs; measures of those inputs and outputs; and the ways of measuring their relationship.

To resolve these challenges, either total- or multi-factor productivity or partial productivity may be used. According to Ball (as cited in Jones and Siag, 2009), total-factor productivity is the ratio of total outputs to the sum of all contributing inputs and associated resource inputs. However, partial productivity usually focuses on just one input or one class of inputs. Sigala (2004) illustrated that the selection of inputs or outputs depends on the approach to productivity definition (partial or total), and on the level of analysis. Partial productivity focuses on specific inputs that can be easily identified and measured. However, because of the synergy among all inputs, a total factor productivity approach has often been adopted.

Chinda (2012) reported a dynamic model to capture the interactions and causal relationships among five factors of productivity. The simulation results revealed that commitment and support from leadership are important in improving productivity in the Thai food industry, as it influences the implementation of four other factors: strategic quality planning, data and information, people, and process management. Results also indicated that it is difficult to improve productivity in the early stages, if the organization does not have enough knowledge and experience. Leaders should encourage two-way communication and provide financial support to aid the productivity improvement program.

Abbott and Carson (2012) analyzed various measures which are used to gauge the levels of productivity and efficiency in the New Zealand construction industry. They identified the strong cyclical nature of productivity in the construction industry and concluded that the growth in productivity was higher in the 1960s and early 1970s than it was in subsequent decades. Strong periods of growth in productivity are associated with strong periods of growth in demand and sharp falls in productivity are associated with slumps in building activity and recessions. They also noted that studies that cover only a limited number of years are generally affected by dominant business cycle (i.e., boom or recession). To avoid this error, they suggested that productivity study should be based on a longer period of time to neutralise the impact of cyclical fluctuations.

\section{Company's Background}

This paper relates to Saha Farms Company Ltd (SFCL) which is a fully integrated organization established in 1969 and is ranked number one frozen chicken exporters in Thailand (Ministry of Finance, 2010). The company's mission is to supply the customers with the high quality poultry products that meet the international standards. The company slogan says that as long as the world turns and human beings need food to survive, 
SFCL will never stop supplying quality foods for all the mankind. SFCL with about 15,000 employees needs to compete with three main competitors with integrated facilities and about 30 competitors that are not fully integrated. Brazil and China are the main international competitors. The company is a family-owned private business with a formal system in place. It operates under a hierarchical structure within the Thai culture where communication flows from the top to the bottom level of management in terms of authority and reverse in terms of the feedback. The products are produced according to the customers' requirements and need no advertisements, because they are fully consumed as there is no scarcity of demand.

Since 1969, SFCL has been operating a fully integrated poultry business consisting of various facilities, such as 12 poultry raising lines, dark-out raising system to separate genders, automatic water and feed systems, evaporative cooling pad system for temperature control, and 24 hatcheries and incubators. The parent stock farm incorporates six farms with a total of 60 poultry raising lines capable of raising 630,000 hens and 94,500 cockerels to produce 63 million eggs annually. Hatchery facility has the capacity to produce 60 million chicks and uses the latest available technology, including computerized focus links and a central control facility, which can check operations at every step of its production process. Broiler farms incorporate the largest and most modern broiler raising lines in Asia, capable of raising 340,000 broilers. Computer-controlled and fully automated raising systems are employed to maintain precise environmental condition, including ventilation, temperature, and humidity appropriate for each stage of development. The facility is hygienically maintained with strict standard to prevent diseases. All processes satisfy strict animal welfare, hazard analysis and critical control points, good manufacturing practice, and other standards. An IT system is used in the diagnosis of animal diseases and a laboratory is certified by ISO/IEC 17025 quality standard.

Further processing plants have an area of 30,000 $\mathrm{m} 2$ and can produce 30,000 tons of cooked and ready-to-eat foods annually, including steamed, fried, and grilled chicken products using state-of-the-art technology from Sweden and the USA. The R\&D facility is staffed with qualified veterinarians and scientists who are specialized in different fields and fully supported by modern instruments and equipment.

SFCL is committed to the highest-quality and best tasting products with around 15,000 employees in the organization. Frozen and cooked poultry products from SFCL have been distributed throughout the nation and worldwide as shown in Figure 2. It has two further processing plants called Saha Inter Foods (SIF) and Golden Line Business (GLB). SIF plant was built in 2001 with a capacity of 4,000 tons per month with eight lines of manufacturing and around 1,400 workers; whereas, the GLB plant was built in 2004 with a capacity of 3,500 tons per month with seven lines of manufacturing and around 1,600 workers.

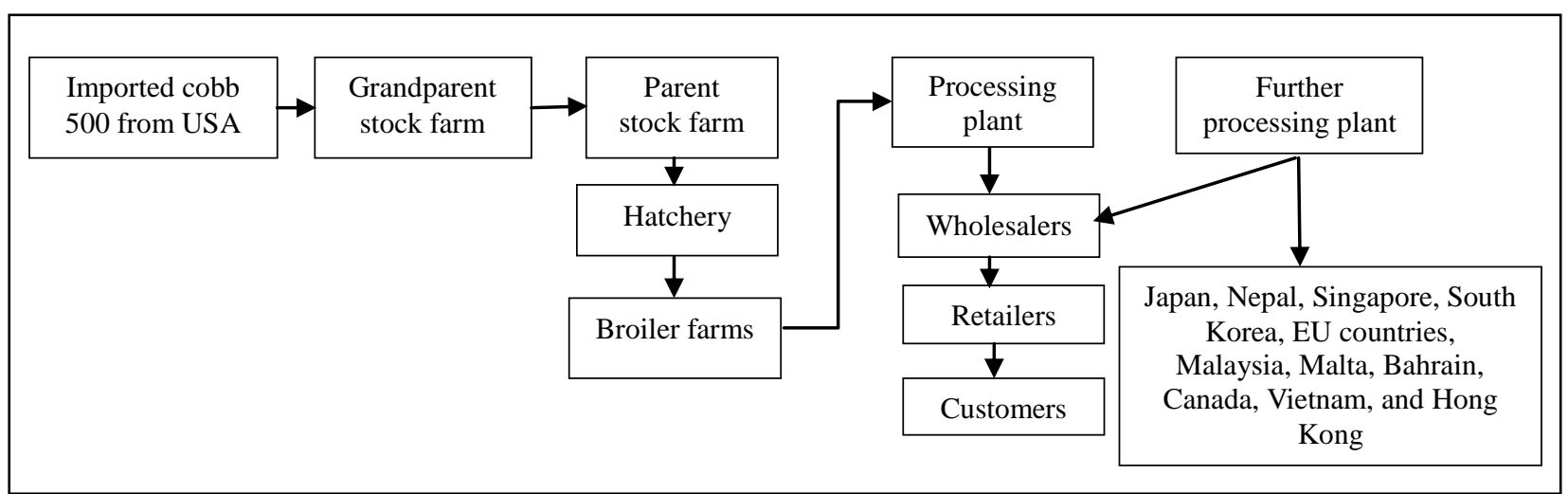

Figure 2. Processing and supply chain in SFCL. 


\section{Main Objectives}

The main objectives of the paper are to: (a) identify and classify different types of cost for productivity analysis; (b) compute and compare labour and multi-factor productivity of two plants of SFCL; and (c) recommend ways to improve the productivity of the further processing plants to produce good quality products and reduce waste or faulty products.

\section{Methodology}

The productivity analysis is based on operational data collected from the two processing plants of SFCL over a period of 15 months. Both labour and multi-factor productivity have been calculated for the two plants using standard methods and compared to identify the reasons behind the differences in their performances. A production system is generally represented by input-output model as shown in Figure 2 and the productivity is expressed as discussed below:

(1) labour productivity: It is the quantity of goods and services that someone can produce with a given expenditure of efforts, usually measured in terms of time spent working or labour time. It is the ratio of the amount of items produced to the amount of labour time used, measured as product per person-hour or person-year:

$$
\text { Labour productivity }=\frac{\text { Number of units produced }}{\text { Labour hours used }}=\text { Units produced/labour }- \text { Hour }
$$

(2) multi-factor productivity: It is a broader view of productivity which includes all the inputs (e.g., capital, labour, material, and energy) used in the production of goods. It is also known as total factor productivity (Heizer \& Render, 2008):

$$
\begin{gathered}
\text { Multifactor productivity }=\frac{\text { Units produced (in kgs) }}{\$ \text { value of (labour }+ \text { materials }+ \text { energy }+ \text { capital }+ \text { miscellaneous) }} \\
\text { Multifactor productivity }=\frac{\text { Units Produced (in } \mathrm{kgs})}{(\mathrm{L} \$+\mathrm{M} \$+\mathrm{E} \$+\mathrm{C} \$+x \$)}=\text { Units produced } / \$
\end{gathered}
$$

\section{Data Analysis and Discussions}

The following analysis is based on various types of operational data collected from the two plants SIF and GLB over a period of 15 months as given in Table 1 .

Table 1

Labour Productivity of SIF and GLB Plants

\begin{tabular}{lllllrl}
\hline Labour productivity of SIF & \multicolumn{5}{c}{ Labour productivity of GLB } \\
\hline Date & Kgs produced & $\begin{array}{l}\text { Labour-min } \\
\text { used }\end{array}$ & Kgs/labour-hr & Kgs produced & Labour-min used & Kgs/labour-hr \\
\hline 2009 & $2,432,300.69$ & 172,390 & 846.56 & $1,366,888.10$ & $73,079.28$ & $1,122.25$ \\
May & $2,619,376.05$ & 182,241 & 862.39 & $1,959,226.60$ & $115,370.85$ & $1,018.92$ \\
June & $2,294,476.17$ & 157,511 & 874.03 & $1,473,339.50$ & $87,537.76$ & $1,009.85$ \\
July & $2,877,906.45$ & 186,777 & 924.49 & $1,790,822.18$ & $114,279.09$ & 940.24 \\
Aug & $2,833,644.73$ & 194,892 & 872.37 & $1,989,131.38$ & $130,355.93$ & 915.55 \\
Sep & $2,980,170.91$ & 190,003 & 941.09 & $1,949,359.12$ & $127,266.97$ & 919.03 \\
Oct & $3,016,005.62$ & 193,858 & 933.47 & $2,118,069.62$ & $135,761.54$ & 936.08 \\
Nov & $2,883,046.08$ & 197,947 & 873.88 & $2,168,700.34$ & $117,052.82$ & $1,111.65$ \\
Dec & & &
\end{tabular}


Table 1 continued

\begin{tabular}{lllllll}
\hline \multicolumn{2}{l}{ Labour productivity of SIF } & \multicolumn{5}{l}{ Labour productivity of GLB } \\
\hline Date & Kgs produced & $\begin{array}{l}\text { Labour-min } \\
\text { used }\end{array}$ & Kgs/labour-hr & Kgs produced & Labour-min used & Kgs/labour-hr \\
\hline 2010 & $2,694,322.99$ & 172,942 & 934.76 & $2,300,744.64$ & $121,114.84$ & $1,139.78$ \\
Jan & $2,417,367.89$ & 151,572 & 956.92 & $2,561,086.90$ & $142,364.62$ & $1,079.38$ \\
Feb & $2,920,904.80$ & 198,368 & 883.48 & $2,375,382.47$ & $136,672.04$ & $1,042.81$ \\
Mar & $2,739,032.44$ & 195,776 & 839.44 & $2,294,824.38$ & $133,559.89$ & $1,030.92$ \\
Apr & $3,287,250.45$ & 225,749 & 873.69 & $2,273,925.71$ & $142,403.98$ & 958.09 \\
May & $3,564,308.59$ & 225,943 & 946.52 & $3,206,975.84$ & $200,148.21$ & 961.38 \\
June & $3,306,379.12$ & 219,546 & 903.60 & $2,330,002.51$ & $158,579.14$ & 881.58 \\
July &
\end{tabular}

Notes. Labour productivity = Kilograms of items produced/Labour-minutes used = Kgs/per labour minute.

\section{Labour Cost of Processing Plants}

According to Table 2, even though GLB plant consists of 1,600 workers, its labour cost is lower than the SIF plant with 1,400 workers. The difference between SIF and GLB is around $\$ 50,379$ per month. For the total labour cost from May 2009 to July 2010, the difference between GLB and SIF is $\$ 755,692$. This is an issue that the company must investigate, because the project did not have information about labour salary on each person. Also, the number of workers was fluctuating for some months.

Table 2

Average Labour Cost of SIF and GLB Plants

\begin{tabular}{lccr}
\hline & \multicolumn{2}{c}{ Labour cost (NZ\$) } & Differences (NZ\$) \\
\cline { 2 - 4 } & SIF (1,400 workers) & GLB (1,600 workers) & 755,692 \\
\hline Total labour cost for 15 months & $8,816,789$ & $8,061,097$ & 50,379 \\
Average labour cost/month & 587,786 & 537,406 & 1,260 \\
Total labour cost/worker & 6,298 & 5,038 & \\
\hline
\end{tabular}

Notes. Labour cost includes every position in the processing plants.

\section{Materials Cost of Processing Plants}

Tables 3 and 4 show that the materials cost (cost of chicken meat, ingredients, and packaging) was the highest among other costs in the processing plants. Data show that the more the SIF and GLB plants produce, the more materials they acquire, which increase the materials cost, and vice versa. However, if the plants can use cheaper suppliers, they would be able to reduce the costs of goods sold within the plant. Table 5 shows the materials cost of two plants.

\section{Energy Cost of the Two Plants}

Table 6 and Figure 3 show that the more the kgs produced, the more the energy cost for both the plants. From Table 7, it is seen that although the plant reduced the kgs produced from June 10 to July 10 in the SIF plant, the energy cost of July 10 was still higher than the June month. This was because the company was building a new processing plant (SIF II) next to SIF I which consumed electric power from SIF I.

\section{Labour Productivity}

As seen from Table 7, the average labour productivity of GLB plant is higher than that of SIF. The difference of productivity between GLB and SIF is around $106.72 \mathrm{kgs} /$ labour-hour $(2,561.31 \mathrm{kgs} / \mathrm{day}$ or 2.56 tonnes/day), because GLB has a bigger and better capacity of machineries than the SIF. 
Table 3

Multi-factor Productivity of SIF Plant

\begin{tabular}{|c|c|c|c|c|c|c|}
\hline \multirow{2}{*}{ Date } & \multirow{2}{*}{ Kgs produced } & Labour cost & Materials & Energy & Total cost & \multirow{2}{*}{$\begin{array}{l}\text { MFP } \\
=\mathrm{kgs} / \$\end{array}$} \\
\hline & & $\overline{\$}$ & $\$$ & $\$$ & $\$$ & \\
\hline May-09 & $2,432,300$ & 464,322 & $11,012,691$ & 482,486 & $11,959,499$ & 0.2034 \\
\hline Jun-09 & $2,619,376$ & 485,553 & $11,147,848$ & 527,003 & $12,160,404$ & 0.2154 \\
\hline Jul-09 & $2,294,476$ & 516,855 & $9,680,724$ & 458,215 & $10,655,794$ & 0.2153 \\
\hline Aug-09 & $2,877,906$ & 499,997 & $12,627,115$ & 549,420 & $13,676,533$ & 0.2104 \\
\hline Sep-09 & $2,833,644$ & 542,846 & $12,274,332$ & 529,035 & $13,346,213$ & 0.2123 \\
\hline Oct-09 & $2,980,170$ & 536,827 & $12,325,182$ & 564,661 & $13,426,670$ & 0.2220 \\
\hline Nov-09 & $3,016,005$ & 559,466 & $12,568,954$ & 522,865 & $13,651,286$ & 0.2209 \\
\hline Dec-09 & $2,883,046$ & 542,541 & $12,293,457$ & 548,246 & $13,384,244$ & 0.2154 \\
\hline Jan-10 & $2,694,323$ & 591,094 & $11,222,254$ & 493,014 & $12,306,362$ & 0.2189 \\
\hline Feb-10 & $2,417,368$ & 602,075 & $10,385,461$ & 510,944 & $11,498,480$ & 0.2102 \\
\hline Mar-10 & $2,920,905$ & 608,007 & $13,221,739$ & 609,522 & $14,439,267$ & 0.2023 \\
\hline Apr-10 & $2,739,032$ & 683,763 & $12,296,905$ & 591,921 & $13,572,588$ & 0.2018 \\
\hline May-10 & $3,287,250$ & 729,236 & $14,530,996$ & 712,880 & $15,973,113$ & 0.2058 \\
\hline Jun-10 & $3,564,309$ & 745,439 & $15,673,885$ & 808,023 & $17,227,347$ & 0.2069 \\
\hline Jul-10 & $3,306,379$ & 708,766 & $13,624,254$ & 851,373 & $15,184,392$ & 0.2177 \\
\hline Total & $42,866,489$ & $8,816,789$ & $184,885,796$ & $8,759,607$ & $202,462,193$ & 0.2117 \\
\hline
\end{tabular}

Table 4

Multi-factor Productivity of GLB Plant

\begin{tabular}{lcccrrr}
\hline Date & Kgs produced & Labour cost & Materials cost & Energy cost & Total cost & $\begin{array}{l}\text { MFP } \\
=\mathrm{kgs} / \$\end{array}$ \\
\hline May-09 & $1,366,888$ & 429,824 & $5,414,362$ & 354,266 & $6,198,452$ & 0.2205 \\
Jun-09 & $1,959,227$ & 425,846 & $8,109,969$ & 433,085 & $8,968,900$ & 0.2184 \\
Jul-09 & $1,473,340$ & 432,951 & $5,490,062$ & 375,280 & $6,298,294$ & 0.2339 \\
Aug-09 & $1,790,822$ & 442,391 & $7,666,043$ & 435,304 & $8,543,737$ & 0.2096 \\
Sep-09 & $1,989,131$ & 485,113 & $8,654,812$ & 447,549 & $9,587,474$ & 0.2075 \\
Oct-09 & $1,949,359$ & 500,468 & $8,091,854$ & 478,374 & $9,070,696$ & 0.2149 \\
Nov-09 & $2,118,070$ & 540,392 & $9,408,986$ & 461,432 & $10,410,811$ & 0.2034 \\
Dec-09 & $2,168,700$ & 567,814 & $9,329,273$ & 489,629 & $10,386,716$ & 0.2088 \\
Jan-10 & $2,300,745$ & 598,312 & $10,205,541$ & 502,675 & $11,306,528$ & 0.2035 \\
Feb-10 & $2,561,087$ & 626,445 & $11,260,708$ & 541,849 & $12,429,003$ & 0.2061 \\
Mar-10 & $2,375,382$ & 604,616 & $10,678,559$ & 517,124 & $11,800,300$ & 0.2013 \\
Apr-10 & $2,294,824$ & 584,586 & $10,042,689$ & 469,058 & $11,096,333$ & 0.2068 \\
May-10 & $2,273,926$ & 618,914 & $9,886,308$ & 481,592 & $10,986,814$ & 0.2070 \\
Jun-10 & $3,206,976$ & 607,626 & $13,611,560$ & 556,832 & $14,776,017$ & 0.2170 \\
Jul-10 & $2,330,003$ & 595,799 & $9,708,550$ & 489,402 & $10,793,750$ & 0.2159 \\
Total & $32,158,479$ & $8,061,097$ & $137,559,275$ & $7,033,452$ & $152,653,824$ & 0.2107
\end{tabular}

Notes. All costs expressed in NZ\$; MFP: multi-factor productivity.

Table 5

Materials Cost of SIF and GLB Plants

\begin{tabular}{lrrr}
\hline & \multicolumn{1}{c}{ SIF } & GLB & \multicolumn{1}{c}{ Differences } \\
\hline Average materials cost & $12,325,720$ & $9,170,618$ & $3,155,101$ \\
Total materials cost & $184,885,796$ & $137,559,275$ & $47,326,521$ \\
\hline
\end{tabular}


Table 6

Level of Production and Energy Cost of SIF

\begin{tabular}{lll}
\hline Date & Kgs of products produced & Energy cost $(\$)$ \\
\hline May-09 & $2,432,301$ & 482,486 \\
Jun-09 & $2,619,376$ & 527,003 \\
Jul-09 & $2,294,476$ & 458,215 \\
Aug-09 & $2,877,906$ & 549,420 \\
Sep-09 & $2,833,645$ & 529,035 \\
Oct-09 & $2,980,171$ & 564,661 \\
Nov-09 & $3,016,006$ & 522,865 \\
Dec-09 & $2,883,046$ & 548,246 \\
Jan-10 & $2,694,323$ & 493,014 \\
Feb-10 & $2,417,368$ & 510,944 \\
Mar-10 & $2,920,905$ & 609,522 \\
Apr-10 & $2,739,032$ & 591,921 \\
May-10 & $3,287,251$ & 712,880 \\
Jun-10 & $3,564,309$ & 808,023 \\
Jul-10 & $3,306,379$ & 851,373 \\
\hline
\end{tabular}

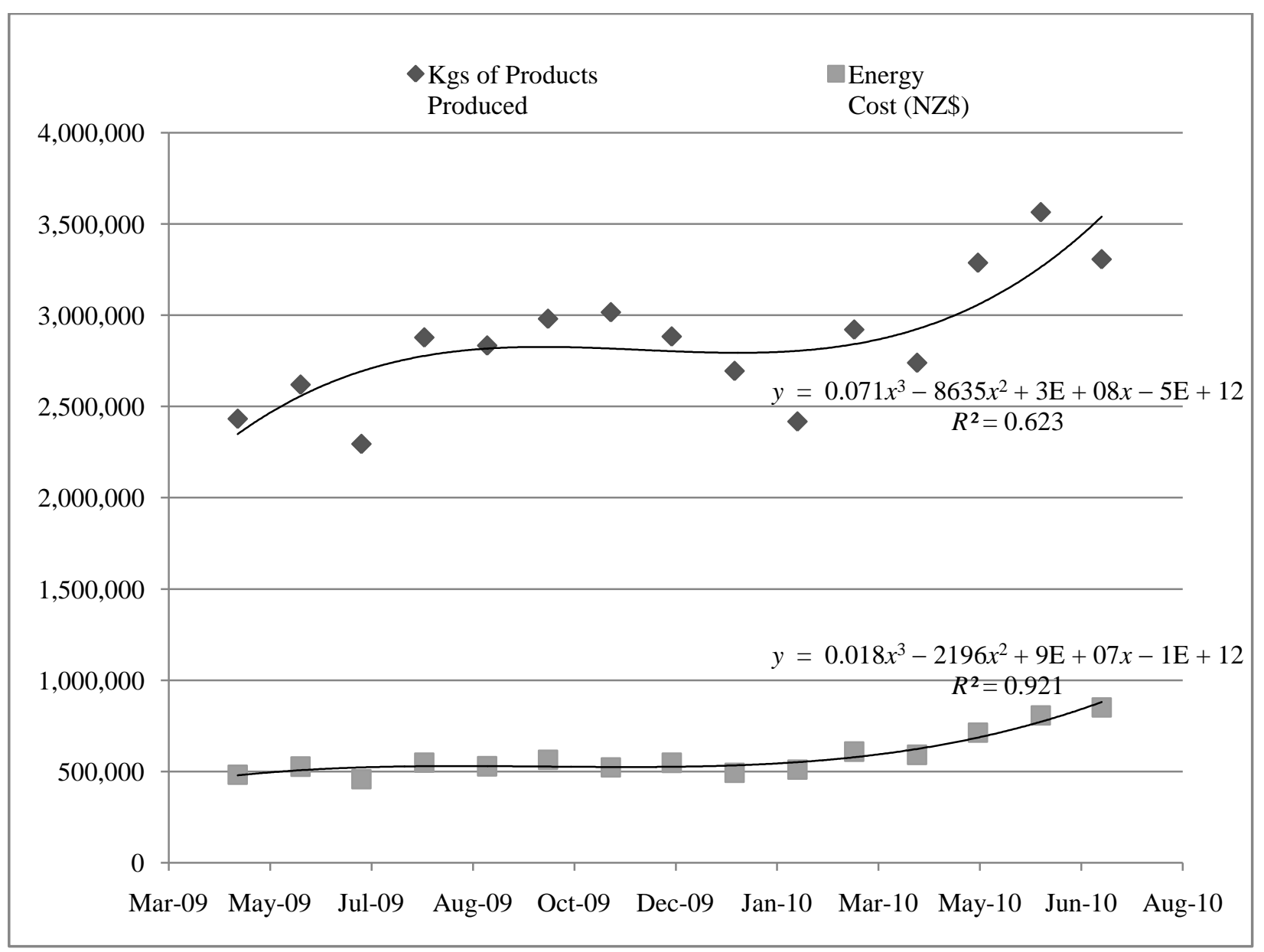

Figure 3. Variation in energy cost with amount of production. 
Table 7

Average Labour Productivity of SIF and GLB Plants

\begin{tabular}{lccc}
\hline & \multicolumn{2}{l}{ Labour productivity } & Differences \\
\cline { 2 - 4 } & SIF & GLB & 1.78 \\
\hline Average kgs/labour-min & 14.96 & 16.74 & 106.72 \\
Average kgs/labour-hour & 897.78 & 1004.5 & \\
\hline
\end{tabular}

\section{Multi-factor Productivity}

It can be seen from Table 8 that the average multi-factor productivity of SIF is a slightly better than GLB for the past 15 months.

Table 8

Multi-factor Productivity of SIF and GLB Plants

\begin{tabular}{lllllll}
\hline & Kgs of products & $\begin{array}{l}\text { Labour cost } \\
\$\end{array}$ & $\begin{array}{l}\text { Materials cost } \\
\$\end{array}$ & $\begin{array}{l}\text { Energy cost } \\
\$\end{array}$ & $\begin{array}{l}\text { Total cost } \\
\$\end{array}$ & $\begin{array}{l}\text { Average MFP } \\
=\mathrm{kgs} / \$\end{array}$ \\
\hline SIF & $42,866,489$ & $8,816,789$ & $184,885,796$ & $8,759,607$ & $202,462,193$ & 0.2117 \\
GLB & $32,158,479$ & $8,061,097$ & $137,559,275$ & $7,033,452$ & $152,653,824$ & 0.2107 \\
\hline
\end{tabular}

\section{Actual Reject and Process Loss}

Actual reject is the product that is inaccurate in terms of specifications (higher or lower weight), shapes (eccentric, bent, or doughnut sticking), etc. These products are sold into the local market. Figure 4 shows that SIF plant has higher rejects than GLB almost every month, because rejects are in proportion to the amount of goods produced.

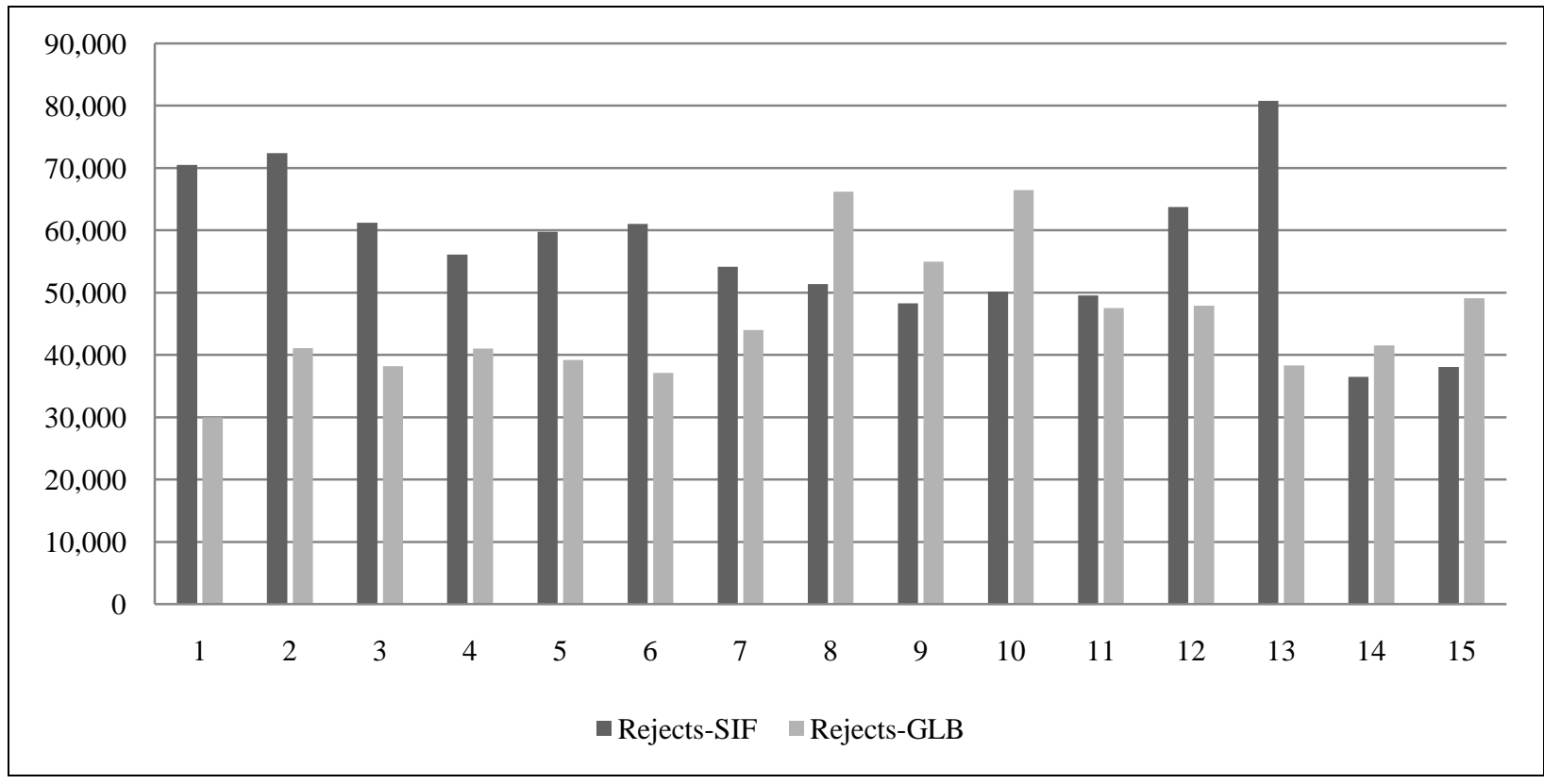

Figure 4. Rejects of SIF and GLB plants.

\section{Process Loss in SIF and GLB}

Process loss is a piece of the product stuck in frying or drying machine or dropped on the floor. These pieces are collected during the cleaning process and are sold out as fish-food (bait) and dog food. Since, SIF machineries have been used longer than the GLB newer machineries, it had frequent breakdowns of 
machineries which resulted in more losses as shown in Figure 5. Moreover, SIF also produced smaller pieces of products than GLB which make the pieces stick to the conveyor belt and the machine easily.

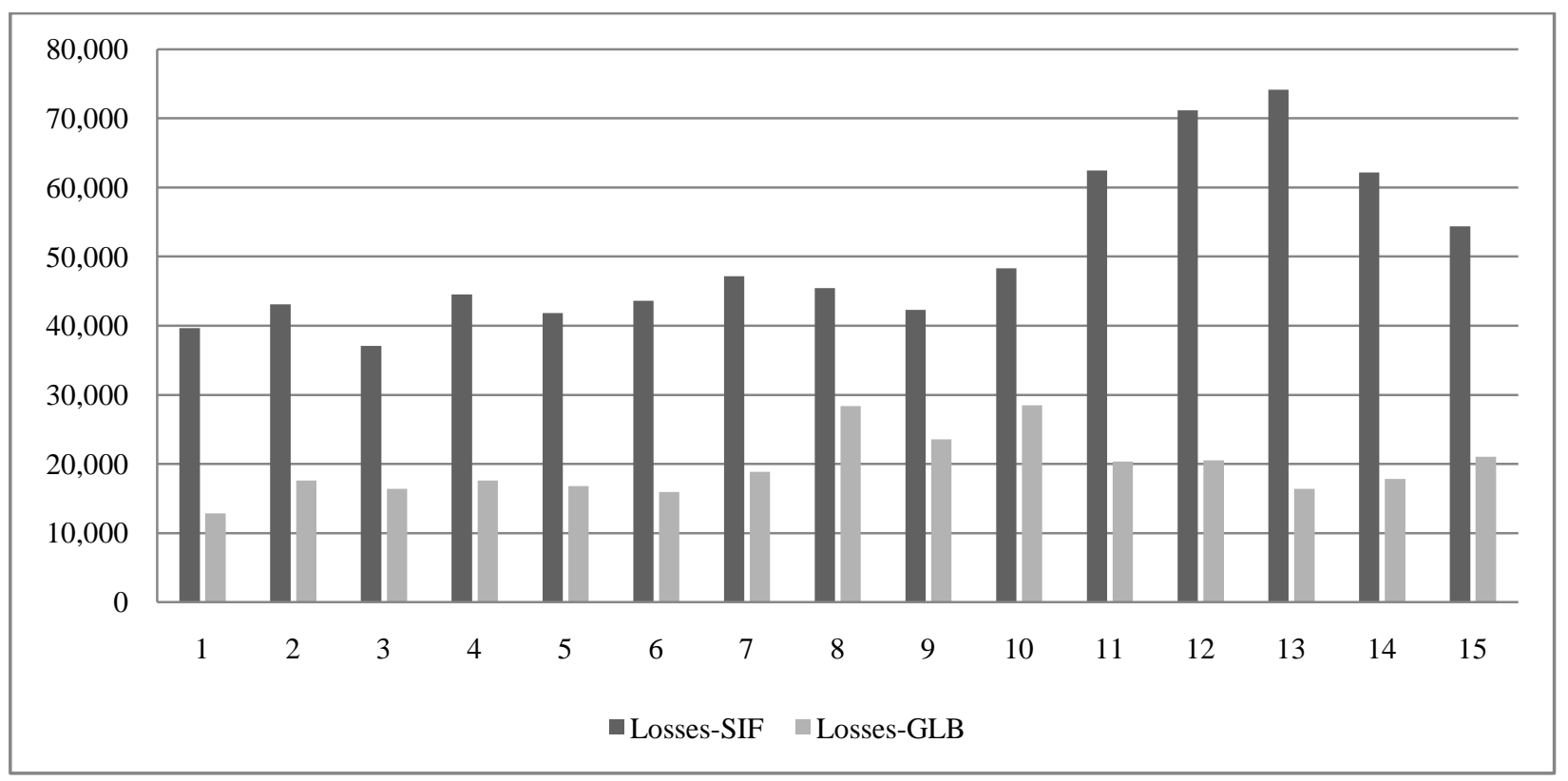

Figure 5. Losses of SIF and GLB plants.

\section{Conclusions}

Based on the operational data analysis, the paper concludes the following points.

Analysis indicates that GLB processing plant has better average labour productivity (16.74 kgs/labour-min) than SIF plant (14.96 kgs/labour-min). There is a difference of about $1.78 \mathrm{kgs} / \mathrm{labour-min}$ (107 kgs/labour-hr). This is because GLB has modern and bigger capacity machineries than SIF which has led to better productivity due to the advantages of modernity and economies of scale. In addition, SIF has frequent breakdowns of machineries, because they have been working longer than GLB. SIF also produced smaller pieces of products, which got stuck with the conveyor belt and the machine easily. SIF could think of redesigning the conveyor belt to suit small sized products. This could improve labour productivity and reduce process loss.

The multi-factor productivity of SIF plant was slightly better than that of GLB due to higher production in kgs of products. As per the data analysis, the GLB labour cost (with 1,600 workers) was lower than that of SIF (with 1,400 workers). The company should investigate into the SIF operations and try to reduce the labour cost to improve its multi-factor productivity.

The average labour cost per month for SIF plant was higher than that of GLB. The company must investigate into this by taking details of wages for every type of labour force and the monthly fluctuations in the number of workers.

It is noted that the materials cost was the highest cost for both the plants. The average materials cost for SIF was greater than that of GLB. The plant should try to explore cheaper suppliers of ingredients, packaging, etc. which would reduce the costs of goods sold within the plant by using bulk purchase discount option.

Analysis also shows that increase in kgs produced, increases the energy cost for both processing plants. However, during June 10 to July 10, even when the SIF plant had reduced the kgs produced, the energy cost of 
July 10 was still higher than the previous month, because the company was building a new processing plant (SIF-2) next to SIF-1 which used power from SIF-1.

SIF had higher rejects than GLB every month, because production of more kgs resulted in more rejects. SIF also had higher process loss than GLB almost every month.

\section{References}

Abbott, M., \& Carson, C. (2012). A review of productivity analysis of the New Zealand construction industry. Australasian Journal of Construction Economics and Building, 12(3), 1-15.

Chinda, T. (2012). A dynamic model of productivity enhancement in the Thai food industry. Engineering Management Journal, 24(2), 15-29.

Heizer, J., \& Render, B. (2008). Operations management (9th ed.). New Jersey: Pearson Publications.

Jones, P., \& Siag, A. (2009). A re-examination of the factors that influence productivity in hotels: A study of the housekeeping function. Tourism and Hospitality Research, 9(3), 224-234.

Ministry of Finance. (2010). Thailand's top ten frozen chicken exporters. Retrieved from http://www.foodmarketexchange.com/datacenter/product/poultry/chicken/detail/dc_pi_pt_chicken0404_01.htm

Sigala, M. (2004). Using data envelopment analysis for measuring and benchmarking productivity in the hotel sector. Journal of Travel and Tourism Marketing, 16(2/3), 39-60. 